\title{
CIUTAT VELLA, CIUDAD BELLA
}

Francesc PEREMIQUEL LLUCH

Ciutat Vella, como muchos centros históricos, ha visto reducirse el número de habitantes casi de manera tan rápida a como se ha ido produciendo la transformación del tejido urbano. Los que van quedando van siendo relegados a los fragmentos menos habitables del tejido. El vaciado físico y funcional, clave en el éxito de la transformación, ha ido fragmentando el tejido en partes y aislándolas entre sí. Y los habitantes, cada vez más, lo son de paso, sobre todo turistas.

La habitabilidad necesaria en la vivienda y en la calle (espacio urbano) ha de ser un objetivo imprescindible de cualquier acción urbanística. La belleza de Ciutat Vella radica precisamente en la posibilidad de ser un espacio habitable y habitado, sano, eficiente y equitativo. La continuidad espacial y el equilibrio funcional son factores esenciales, para mantener el carácter del lugar, su identidad y la vida cotidiana de quien vive y trabaja. Lo contrario es lo que en términos pictóricos denominaríamos naturaleza muerta.

Espacio habitable, Centro Histórico, Espacio cotidiano

\section{OLD CITY, BEAUTIFUL CITY}

Ciutat Vella, like many historic centers, has seen the population decline almost as rapidly as the transformation of the urban fabric. Those that remain are being relegated to the less habitable fragments of the fabric. The physical and functional emptying, key to the success of the transformation, has been fragmenting the tissue into parts and isolating them from each other. And the inhabitants, more and more, are passing by, especially tourists.

The habitability required in housing and in the street (urban space) must be an essential objective of any urban action. The beauty of Ciutat Vella lies precisely in the possibility of being a livable and inhabited space, healthy, efficient and equitable. Spatial continuity and functional balance are essential factors to maintain the character of the place, its identity and the daily life of those who live and work. The opposite is what in pictorial terms we would call still life.

Living space, Historical Center, Daily space.

\section{Ciutat Vella, Ciudad Bella}

A mediados del siglo XIX surge un concepto urbanístico con denominaciones varias -casco antiguo, ciudad vieja, centro histórico-, que nace en contraposición a la realidad emergente de la construcción de la nueva ciudad por extensión de la existente. De hecho la idea que genera la adjetivación de antigua, vieja o histórica, de una parte de la ciudad es el resultado de la aparición de una ciudad moderna, nueva, contemporánea, basada en otra lógica urbanística, que tiene como finalidad superar las limitaciones de la ciudad existente en términos higiénicos, funcionales y sociales.

La nueva ciudad, se pretende más sana en términos ambientales, más eficiente en términos económicos y más equitativa a favor de las clases sociales urbanas emergentes. Ambiciones que ciertas partes de la ciudad consolidada no pueden satisfacer de manera efectiva. La ciudad preexistente no podrá alcanzar estos requisitos, en general, de ningún modo, a no ser que sufra una transformación o renovación profunda de sí misma. En ese contexto, era por tanto necesario, que esta parte de la ciudad, si quería mantener la competitividad con la ciudad nueva, adaptara sus condiciones de habitabilidad a las nuevas demandas sociales que, en términos actuales, denominaríamos sostenibles.

El urbanismo moderno en los años treinta, pero también con anterioridad Cerdá, Haussmann, entre otros, en la búsqueda de una ciudad higiénica, racional y equitativa, plantean el derribo de la ciudad histórica y su reconstrucción según los nuevos principios inspiradores de las practicas urbanísticas emergentes. El Plan Voisin, por poner un ejemplo, siguiendo estos criterios propone reconstruir el centro de Paris sobre el derribo de los barrios tradicionales de las áreas centrales de la ciudad.

Los grandes males de estas partes de ciudad y las dificultades para responder a los nuevos retos urbanos eran, y todavía son, aquellos derivados de la obsolescencia física, funcional y tipológica del tejido. Obsolescencia física debido a las malas condiciones constructivas de los edificios (no todo son edificios de "piedra"); funcional y tipológicamente por no ser adaptables a los usos y costumbres emergentes y no disponer de espacios adecuados a los estándares y necesidades funcionales requeridos.

Muchos edificios no cumplen con las reglas de habitabilidad interior necesarias o deseables. Las infraestructuras, las calles y los espacios libres, 
la otra parte de la ciudad donde son exigibles condiciones adecuadas de habitabilidad, tampoco cumplen los mínimos imprescindibles. Para la correcta habitabilidad exterior es requisito fundamental garantizar una buena accesibilidad y la adecuación de las infraestructuras a los sistemas de movilidad; el acceso a los servicios urbanos y equipamientos, y unos espacios libres suficientes. Los cascos antiguos acostumbran a tener limitaciones de acceso por el tamaño de sus calles, no admiten los sistemas de movilidad y transporte habituales de manera eficiente en su interior, y los espacios libres y las infraestructuras acostumbran a ser insuficientes e ineficientes.

Es en este contexto que la obertura y el sventramento, como medida quirúrgica y modernizadora, se generalizó en las ciudades, en las de mayor tamaño al principio y posteriormente, en las demás. A estos efectos, el tamaño de la ciudad importa y mucho. Importa porque el impacto y el efecto sanitario de las acciones no es el mismo en las ciudades mayores con gran necesidad de transformación estructural que en ciudades de pequeño tamaño, con cascos antiguos más limitados.

El derribo constructivo, es decir, derribar para modernizar, para rejuvenecer, para poner al día se convirtió en un instrumento, no solo útil, sino necesario y en muchos casos imprescindible. La cirugía urbana fue, y es todavía hoy, una técnica de resolución de patologías diversas. En algún momento abriendo en canal; extirpando pequeños tumores existentes o emergentes o sacando quistes; mediante microcirugía más o menos invasiva, resolviendo deformaciones o malformaciones e introduciendo elementos nuevos a modo de prótesis. En ciertos momentos fue tal el grado de necrosis que se creyó necesaria la amputación total, como mal menor. Más recientemente, la cirugía estética, los trasplantes o los tratamientos crónicos en muchos casos han permitido mantener vivos organismos muy enfermos (y a pesar de ello, larga vida les de Dios...)

Estos tratamientos han sido utilizados con mayor o menor éxito en múltiples situaciones, lo que hace pensar en cualquier caso, en la plena vigencia de los mismos. El derribo como expresión básica de la renovación, siempre ha estado presente y ha sido necesario. No obstante, ha ido modificando su alcance a lo largo del tiempo, intentando ser lo menos agresivo y costoso posible. ¿Que derribar y que conservar?, ha sido una pregunta constantemente planteada.

No obstante, la capacidad de sobrevivir de ciertas partes de la ciudad, a pesa de sus muchas patologías, es sorprendente, y mucho más su capacidad para adaptarse a circunstancias cambiantes. Y lo han hecho adaptándose y reconvirtiéndose en espacio monumental, institucional, comercial o turístico. Un lugar más para visitar, que para vivir; para representar, para ver o para entretener más que un lugar para habitar. A menudo perdiendo una característica esencial para ser ciudad: ser un espacio habitable, para vivir cotidianamente, ordinariamente. Convirtiéndose poco a poco en una naturaleza muerta.

Vivir en esta parte de ciudad, en muchas ciudades, no es fácil, ni cómodo, ni siempre agradable. Vivir en esta parte de ciudad supone aceptar una condiciones de vida a veces lamentables, y renunciar a algunas prestaciones imprescindibles como un mal necesario para la preservación de unos valores o la protección de un "patrimonio", que no todos sienten como propio.

Conservar o derribar no es una acción binaria de uno o cero, como se viene planteando, sino dos partes de una ecuación no excluyente. Derribar para conservar es seguramente la opción más generalizada, pero también hay que derribar para trasformar, para construir de nuevo, de otro modo, con otras prestaciones, para otras necesidades. No todo se puede conservar, no todo se debe conservar.

La cuestión, no obstante, no radica en el porqué, que tiene respuestas múltiples, muy razonables todas, a favor y en contra, sino el qué, para qué y el cómo de las dos opciones, derribar o conservar. Esta pregunta nos lleva a una cuestión que no es propia de cada caso, sino que responde a un objetivo superior, y más noble si cabe, que es sobre las prestaciones exigibles a la ciudad y a los edificios que la conforman, sea nueva o vieja, en el momento presente y para el devenir futuro y como y a que coste esta mejora se materializa.

La respuesta la podemos encontrar en un balance necesario entre prestaciones deseables para unos y los valores a preservar para otros. En este dilema los actores son relevantes. Para unos la conservación, a toda costa, aunque no sirva, no sea útil, sea insalubre o deficiente, y a cualquier precio, es lo fundamental. Donde la memoria a menudo pesa más que la historia. Y la subjetividad, más que la objetividad. Para otros, los que allí viven, la mejora de las condiciones de habitabilidad es esencial e irrenunciable. ¿Es posible compatibilizar ambas opciones?

Los valores a preservar son en general de carácter identitario y emocional, son los valores de la memoria y la tradición, siempre de carácte subjetivo, pero no por ello menos importantes. Lo preocupante es que habitualmente los defensores de estos valores no son los habitantes. Para ellos todo se debe reutilizar, reciclar, reconstruir, rehabilitar, re-habitar, reproducir... en definitiva mantener unos soportes deficientes y una imagen pintoresca como sea. Cualquier tiempo pasado fue mejor y hay que mantener vivo el recuerdo.

Para los habitantes el problema es reequipar, renovar, es poner la ciudad al día. Tener las mismas prestaciones que otras partes de ciudad. Disfrutar de las mismas condiciones de habitabilidad. 
Una buena parte del carácter del espacio, tal y como hoy lo conocemos, proviene de la intensidad de edificación existente, más elevada de lo deseable, que conforma un espacio con deficiencias insubsanables con las técnicas de rehabilitación habituales. A saber, el exceso de edificabilidad, la angostura de las calles, la insuficiencia del tamaño de las manzanas, la estrechez de la parcelas, en términos urbanos y las deficiencias de asoleamiento y ventilación, los déficits de accesibilidad vertical en los edificios, la excesiva profundidad edificable, las distribuciones interiores deficientes, los tamaños insuficientes, la debilidad y limitaciones de los soportes etc., de los edificios en particular, son patologías comunes. En este contexto lo mejor seria derribar.

Entre unos y otros, están los que de todo sacan rédito. Si hay que conservar lo viejo, que sea para los turistas, los habitantes temporales, los comerciantes, etc.; usuarios no muy exigentes, que aprecian valores superficiales conscientes de la temporalidad, excepcionalidad de uso o la rentabilidad económica. E decorado, la imagen de cartón piedra, el tipismo para un determinado imaginario colectivo es suficiente. Convertida en parque temático, por trozos y a ratos, parece una ciudad viva, aunque en realidad no viva casi nadie.

Si, por el contrario, se puede construir de nuevo, que sea lo más económico y pragmático posible, aunque se rompa el carácter, se modifique la imagen o se destruya la memoria, sin vergüenza ni escrúpulos, con pretensiones y pocas soluciones, como si la ciudad vieja o histórica fuera un lugar cualquiera, en el que actuar con impunidad que da la racionalidad constructiva y la eficacia en la promoción.

La ciudad vieja se cae en muchas ciudades, no solo física, sino también socialmente, dejando de ser un espacio deseable para vivir. Degradación física y humana que comporta el abandono y el olvido, a menudo intencionado. Aquí la memoria es selectiva, anecdótica y pícara. Un sitio del que hablar o sobre el que escribir pero en el que no es fácil vivir. Fernández (20 I2) aborda la presión y asedio sobre el Raval en aras a la expulsión de sus habitantes y actividades y posibilitar su transformación. Los que se quedaron al fin al cabo eran ciudadanos normales, de los que se fueron no quedó rastro.

Busquets (2006) pone de relieve el creciente éxito de las políticas de revitalización de los centros históricos, cuando apenas 50 años antes, en la postguerra, se consideraba a la ciudad existente como un espacio sin valor sobre el que actuar haciendo tabula rasa.

La transformación interior de las ciudades y su puesta al día, ha sido posible gracias a la extensión urbana, que ha permitido descongestionar los centros y reequilibrar la ciudad en su conjunto. Con ello no obstante se han perdido muchos de los atributos urbanos de esta parte de la ciudad. Muchas funciones tradicionales han ido desapareciendo.
La revitalización de los centros históricos como espacio comercial, turístico, administrativo, es un hecho. Pero en la mayoría de casos es una intervención cosmética. Siguen habiendo temas sin resolver y la polémica se mantiene alli donde el tema es de habitabilidad, las deficiencias persisten donde la capacidad del soporte es insuficiente.

"Lo peor es la nueva arquitectura" decía J. Acebillo en relación a las reformas en Ciutat Vella, ${ }^{1}$ en un debate en el Colegio de Arquitectos. En el mismo debate, P. Serra decía "No hemos sabido solucionar el problema de la vivienda. La que se ha hecho no es adecuada”. En ningún caso se ponía en duda el modelo de intervención, basado en una intervención selectiva, estratégica y oportunista, que utiliza las ocasiones para actuar y que bien describe P Cabrera (1998).

Desde el principio el riesgo de la conservación fue pensar más en la "piedra" que en las personas. Esto en muchos casos ha llevado a la gentrificación, con la consolidación de viviendas y comercio para las clases acomodadas o habitantes de paso, aquí y en muchas ciudades. La intervención pública y puesta en valor ha supuesto la expulsión de los habitantes que, como la propia ciudad, han quedado obsoletos, por falta de capacidad económica, por origen étnico o por edad.

En todo caso, la gentrificación es un fenómeno inevitable cuando se produce la mejora del espacio urbano con carácter genérico y sin atención específica a sus residentes. Pero no por ello hay que dejar de hacerlo. Los residentes, como es normal, aspiran a la mejora de las condiciones del entorno y reivindican su transformación. Lo que no es justo que se esto se vuelva contra ellos.

Es curioso observar que todos los casos de éxito, entre los que se cuenta Barcelona, que llenan páginas de revista y estanterías de biblioteca, pocos tengan como objetivo principal, la vivienda y el espacio habitable. En general la vivienda solo es el complemento necesario y útil para justificar la intervención, sirve para el realojamiento y minimiza el impacto político de la expulsión. En un proceso de recuperación de este espacio urbano, la vivienda debería convertirse en un objetivo prioritario, no solo por y para sus habitantes sino por su función misma. Y su manera de insertarse debería tener en cuenta las características morfológicas, geométricas y métricas, que caracterizan el tejido. Los buenos proyectos de transformación urbana lo han tenido en cuenta.

El vaciado urbano no resuelve estos problemas, ya que solo mejora la situación de los edificios próximos o directamente vinculados; mejora los estándares del conjunto pero no las condiciones particulares de muchas construcciones, que van a ir quedando como reducto insalubre. La práctica ampliamente utilizada, de vaciar para disponer de espacios libres, no solo consigue desfi- 
gurar sino que rompe con las continuidades características del tejido. La estrategia de reequipar con equipamientos de gran escala, también muy utilizada, abunda en la consolidación del vacío, la discontinuidad aísla las partes habitadas, contraponiendo áreas con exceso (hacinamiento) al lado de áreas con defecto (sin habitantes). Es interesante observar que donde la residencia permanece, ni la intensidad, ni la densidad bajan. Y, la calidad de la vivienda y la habitabilidad, no mejoran. Solamente cambian las cosas cuando deja de vivir gente y la vida urbana es la que genera el visitante ocasional.

Las nuevas condiciones de habitabilidad han de asumir también el reto contemporáneo de la preservación de la memoria y la identidad (¡quien pierde el origen, pierde la identidad!). Esta es una idea que se impone a partir de los años 70, por dos razones: una, la recuperación del concepto de urbanidad ampliamente reivindicado como un valor esencial de la ciudad y la otra, el hecho de que las partes de la ciudad no se distinguen ya por sus estándares generales (prestaciones mínimas imprescindibles de habitabilidad urbana), sino por sus prestaciones específicas. En una ciudad que se entiende también como producto, las características específicas de sus partes son un hecho diferencial y valioso a tener en cuenta. Existe una cultura urbanística que demanda de los proyectos que se realizan sobre la ciudad un cuidado especial sobre la realidad existente y una atención al carácter previo del espacio, más formal que sustancial, sin entender que el carácter también lo imprimen las personas. Sin ellas no hay urbanidad posible. Por tanto, jde qué urbanidad hablamos?

Los centros históricos de muchas ciudades catalanas y españolas han sufrido en las últimas décadas graves procesos de deterioro y abandono (Lleida, Balaguer, Tortosa,... por poner unos ejemplos), a pesar de mucha inversión pública y de intentos de salvaguardarlas, de nada ha servido el vaciado selectivo, la incorporación de grandes equipamientos o reurbanizaciones sistemáticas. Otras en cambio han sobrevivido, aunque sufren situaciones de degradación puntuales y fácilmente subsanables (Reus, Olot,...) gracias a un proceso constante de renovación interior con ciudadanos habitándolas. Otras en cambio, donde el soporte físico era de más calidad para vivir han sido conservadas (Girona, Toledo o Santiago de Compostela). Y lo que las ha conservado ha sido la gente viviendo alli.

Estas tres situaciones: abandono, renovación y conservación se producen de manera simultánea en el caso de Barcelona, pieza de un tamaño excepcional y de confluencia de situaciones diversas.

En el caso de Barcelona conviven diversos tiempos y distintos caracteres. Ciutat Vella no es un conjunto uniforme, es el resultado de adiciones, yuxtaposiciones y superposiciones sucesivas a lo largo del tiempo, con distintas
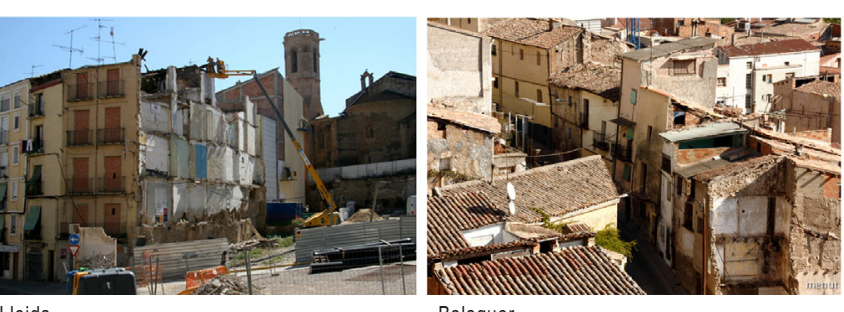
Balaguer
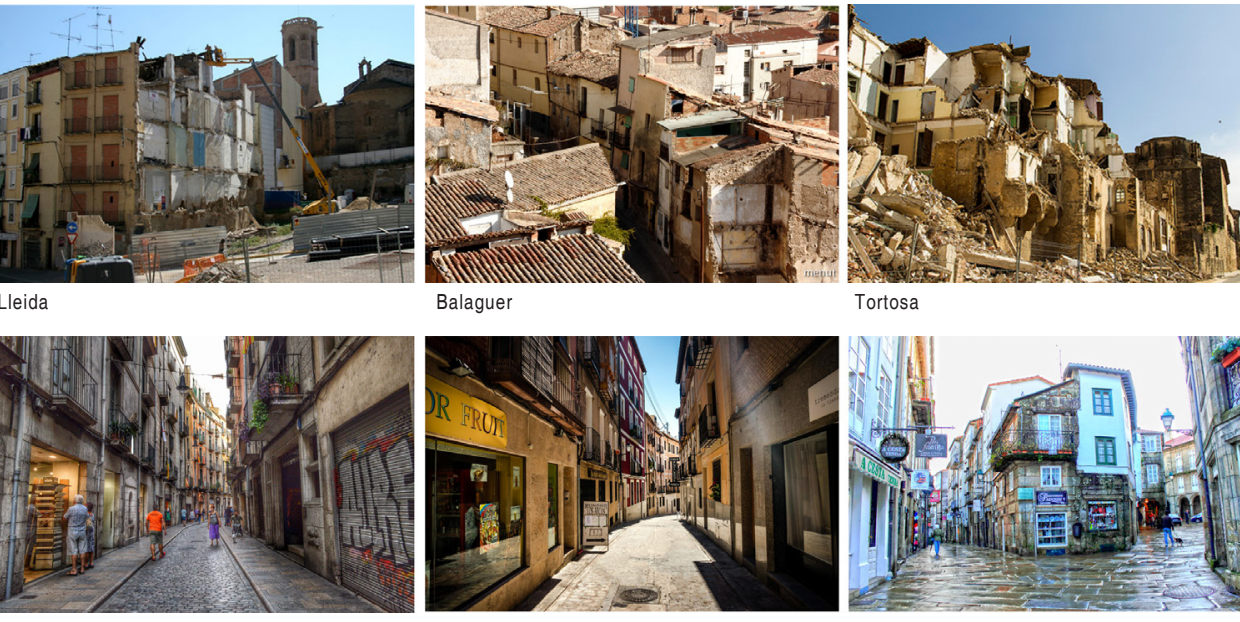

Tortosa

Girona

Toledo

calidades. Superposiciones de cosas, unas encima de otras, y yuxtaposiciones, unas al lado de otras. De hecho se pueden reconocer muchas formas distintas de hacer, como apunta J. Busquets (2003), en una parte de ciudad que ha sido renovada y es permanentemente actualizada, en un proceso de constante reconstrucción sobre sí misma. El resultado, al final, es un ciudad no tan vieja desde el punto de vista temporal, pero en muchas de sus partes deteriorada.

Si bien la imagen (histórica y patrimonial) es muy importante desde un punto de vista emocional, es mucho más relevante la impresión que ejerce sobre el observador, habitante o no, el aspecto del lugar en algunas partes. Un aspecto de lugar envejecido, anticuado, como perteneciente a otro tiempo, deteriorado por el paso de los ańos, obsoleto e insalubre.

¿Estamos condenados a mantener situaciones no deseables por el hecho de existir? ¿Es posible plantear ciudad nueva con los valores de antes? ¿Es posible proyectar ciudad nueva con criterios de la ciudad histórica? Por todo ello debemos intervenir, antes de que la única opción sea derribar y vaciar.

Carlos Itriago (2006) en Copias, transformaciones y omisiones: reconstrucción de la ciudad devastada nos plantea algunos interrogantes útiles también en la reflexión sobre la ciudad vieja o los centros históricos. ¿Reconstruiríamos una copia mimética de la ciudad existente, si por alguna razón esta fuera devastada? O por el contrario, ¿Utilizaríamos selectivamente la memoria para equilibrar nuevo y antiguo? ¿Prescindiríamos de la memoria para dar paso a los nuevos tiempos? ¿Qué debemos recordar y qué es mejor olvidar? 


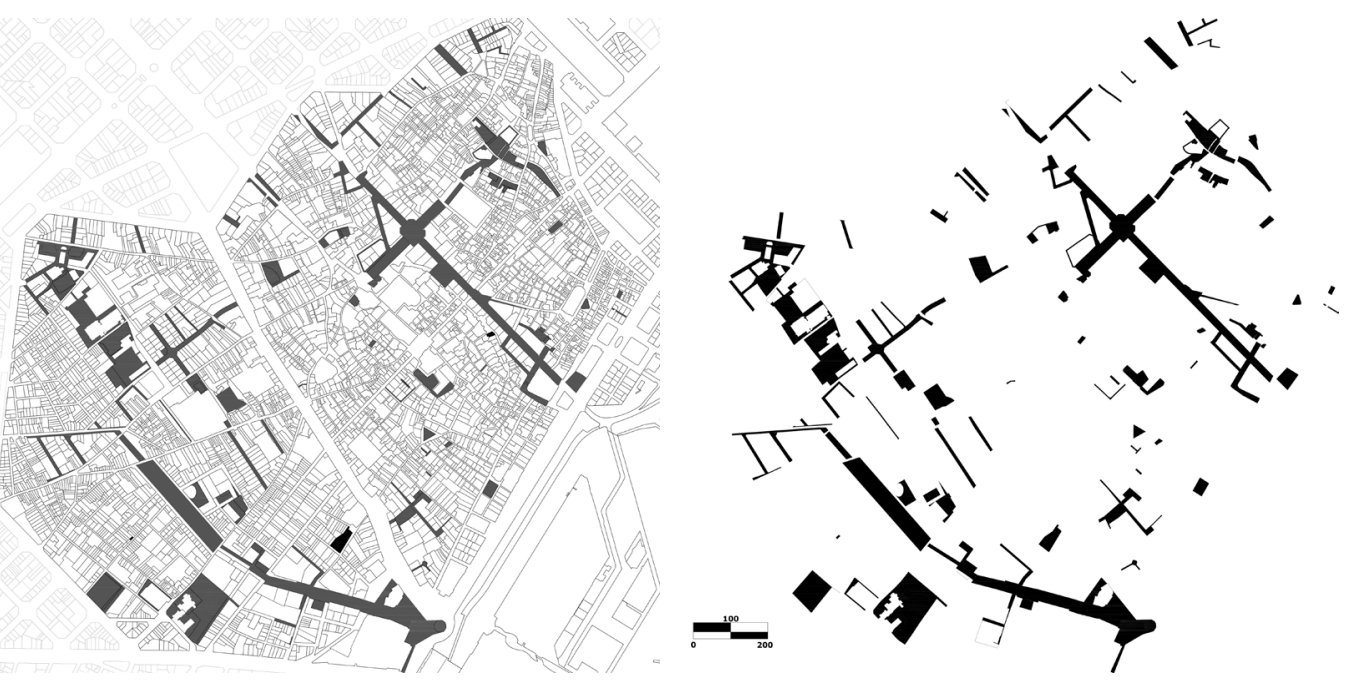

Plano de perturas y ampliaciones de calles y areás liberadas de edificación producidas en Ciutat Vella desde 859 hasta la actualidad. Fuente: Andrea Ordónez, actualización a partir del plano de Busquets,J (2003).

Probablemente la solución sea sencilla aunque su implementación no lo sea tanto. Recuperar la habitabilidad pasa por reequilibrar en lugar de vaciar unas partes para mantener otras insalubres. Más que vaciar, lo que se debería hacer -o lo que se debería haber hecho- es evitar o corregir las disconformidades. Solo un edificio en los últimos cuarenta años ha disminuido su altura o reducido la edificabilidad y es justamente el del Ayuntamiento. Ningún espacio interior de manzana, hasta donde conocemos, ha sido recuperado en Ciutat Vella. Todo lo demás ha tendido, o bien a vaciar, con enorme coste para las arcas públicas, a cambiar de uso, o bien a consolidar el aprovechamiento existente, en beneficio de los propietarios, algunas veces con subvenciones públicas.

Cada vez más, Ciutat Vella aparece como un fragmento urbano troceado y discontinuo, con grandes vacíos y fragmentos insalubres, donde la solución no pasa ya por vaciar más, sino por descabezar (escapçar en catalán) aquello que está por encima de los limites admisibles, deseables, adecuados. El cambio de estrategia que afectaría seguramente a los propietarios más que a los usuarios, que tenderán al abandono y la degradación del espacio como medida de presión sobre los poderes públicos. Para ello hay que estar preparados y prevenidos, estas tácticas son conocidas (ya se han ensayado antes). Mantener lo viejo, obsoleto e insalubre por temas cuantitativos de aprovechamiento urbanístico (edificabilidad y ocupación consolidada) debería estar fuertemente penalizado y no poner al día los edificios y adaptarlos a las necesidades contemporáneas, también.

\section{Ciudad bella}

La urbanidad que respira esta parte de ciudad la convierte en ciudad bella. Este es uno de los retos imprescindibles a afrontar de la ciudad contemporánea y uno de los retos fundamentales de la transformación interior de las ciudades. Urbanidad que nace de entender la ciudad como este espacio de relaciones múltiples, complejas y diversas. En donde la vida cotidiana debe ser compatible con la excepcionalidad del visitante. La urbanidad es un atributo vinculado a lo urbano, y por tanto se juega en el terreno de la relación entre la infraestructura y la arquitectura, que se hace relevante en el nivel del espacio más perceptible: la planta baja y la calle, en los elementos de transición interior y exterior, en el contacto entre lo público y lo privado. La urbanidad no la genera ni el vacío ni la discontinuidad, ni los recintos singulares, ni tampoco las actividades excepcionales.

Ruskin a mediados del siglo XIX destaca el valor de la arquitectura doméstica en los centros históricos, cuya belleza radica en su continuidad, por su papel conformador del tejido (Vergara, 2004). La restauración fue el soporte de la conservación en los primeros tiempos. Esta visión romántica de la ciudad vieja, lleva a la protección de amplias zonas urbanas, que contrasta con la tolerancia/ permisividad en las zonas no protegidas.

Camilo Sitte, a finales del siglo XIX, propone el estudio de las plazas y espacios de la ciudad histórica como referente para la construcción de la ciudad nueva, entendiendo que el valor del patrimonio se encuentra precisamente en estos espacios urbanos, su trazado, morfología e imagen.

G. Giovannoni, autor que sistematiza la idea de patrimonio urbano, defiende que los centros antiguos deben ser espacios de vida cotidiana y liberados de actividades incompatibles con su forma. Además de espacios monumentales y decorados pintorescos, pueden ser catalizadores de configuraciones espaciales distintas de la ciudad moderna, donde la vivienda popular debe jugar un papel relevante, que se apoye en la calidad del espacio urbano que aporta el legado histórico, con una política de vivienda específica para estas partes de ciudad.

Lo que la ciudad histórica no tiene, en general, son condiciones de habitabilidad higiénica o eficiencia funcional, ni tampoco de equidad social. Lo que aporta son valores culturales y sociales intangibles, expresados en el espacio exterior de los edificios, muchos comercializados como producto turísticos.

La morfología urbana, geometría y proporción deviene un aspecto clave. En la reconstrucción de la ciudad devastada es tanto o más importante la forma exterior, la volumetría, las secuencias espaciales y las continuidades, que lo que ocurre en el interior de los edificios, que puede ser perfectamente puesto al día y renovado. Es lo que en definitiva asegura el éxito o fracaso de la intervención. Para muchos la memoria no deja de ser un lujo inalcanzable (o no la tienen o 
mejor es olvidar) y que además les es ajena, aunque nos digan que es de todos. Recuperar la higiene, la equidad y la eficiencia es lo que hará de ella una ciudad sostenible y durable.

Según Busquets (2006), Giovannoni plantea tres cuestiones clave para la intervención: 1) Cualquier fragmento urbano antiguo debe ser integrado a la vida contemporánea, participando de los instrumentos reguladores y de equidistribución que legitimen sus dinámicas, lo que quiere decir que debe ser tratado como cualquier otra parte de la ciudad a estos efectos. 2) El ambiente urbano, y en consecuencia la continuidad con el entorno, es esencial para preservar el carácter lo que implica preservar las relaciones morfológicas entre los componentes. 3) Los conjuntos urbanos necesitan para su preservación clarificar-aclarar espacios, que no vaciar el tejido, ya que vaciar implica introducir espacios de una escala que no es la propia del lugar, lo que supone poner en orden las disconformidades urbanísticas.

Determinadas corrientes de pensamiento consideran el patrimonio edificado de la ciudad histórica, no solo como un bien cultural, sino como un bien en si mismo, con valor social y económico. Frente al vaciamiento destructivo de los centros históricos para facilitar la renovación tipológica plantean operaciones de saneamiento, eliminando añadidos, densificaciones y reformas inadecuadas y recuperar la estructura original, también las intensidades y densidades de edificación. Todo ello destinando fondos públicos de la producción de viviend a la recuperación del interior de la ciudad.

En el caso de Barcelona la inversión en Ciutat Vella ha sido ingente pero no ha resuelto los problemas de habitabilidad residencial. Y no hay proyectos significativos sobre el espacio residencial, porque la inversión pública se ha realizado mayoritariamente en los espacios públicos y comunes y no en las viviendas, y la recuperación del espacio urbano se ha confiado a instituciones ajenas al tejido residencial (universidades, equipamientos culturales, administraciones, etc...) para finalmente abrir las puertas a una especulación inmobiliaria en forma de apartamentos turísticos y similares.

\section{Epílogo}

Buena parte de la ciudad contemporánea, en especial en sus partes más consolidadas son ciudad vieja, ya histórica. Vieja porque los años pasan, histórica porque tiene pasado.

En pocos años, sino ya, esta reflexión se extenderá a toda la ciudad. La parte más reciente ya tiene una edad. En muchas partes ya se reconocen los problemas de la ciudad vieja: áreas física y sociológicamente degradadas, con prestacione insuficientes, trazados ineficientes, soportes limitantes... donde seguramente es más costoso mantener que renovar. Pero siempre, desde la perspectiva de la propiedad, es mejor conservar, a cualquier precio, que retrodecer o disminuir alturas. La disconformidad es una situación generalizada, que tiende a más.

A día de hoy hay una idea ampliamente implantada, de que la ciudad no debe extenderse, sino intensificarse y compactarse. Para ello la idea es incrementa siempre, poner más y más, y si no cabe, ponerlo al lado. Vaciar para compensar, con un alto coste público y dudoso resultado urbano, desequilibrando la ciudad (mucho espacio público y un deficiente espacio habitado). Los déficits de muchas manzanas y edificios no se resuelven de manera equilibrada, uniforme y homogénea, sino en acciones puntuales y selectivas. ¿No sería mejo reducir algunas plantas de manera homogénea, vaciar patios interiores, reducir profundidades, incrementar patios de ventilación, desocupar plantas bajas,.. etc., que romper o desgarrar el tejido? ¿No sería oportuno cuestionar una rehabilitación que solo sirve para mantener las disconformidades y los excesos, y plantearse una reconstrucción del tejido equilibrado? ¿No es momento de descabezar? ¿No es momento de poner límites y quitar barreras? ¿Por qué no hacer una transición de Ciutat Vella a ciudad bella, entendiendo esta como una ciudad amable, sensible y habitable?

Algunos arquitectos afirman que las personas deben adaptarse a los espacios y no al revés. Y tienen en parte razón, como criterio general, pero amablemente discrepamos, porque en muchos espacios más que adaptarse, lo que toca es aguantarse, y si no, que se lo pregunten a los que malviven en espacios inhabitables de muchos edificios. Para ellos lo mejor sería derribar y volver a empezar. Y reconstruir no por obsolescencia (porque no hay más remedio), sino por eficiencia.

\section{BIBLIOGRAFÍA}

ARROYO, F. (4 de abril de 2000). En Ciutat Vella predomina la mala arquitectura. El País. BUSQUETS, J. (2003). La ciutat Vella del Centro Histórico de Barcelona. Un pasado con futuro. BadaIona: Ara Libres.

BUSQUETS, J., \& CORREA, F. (2006). Cities $X$ lines : a new lens for the urbanistic project. Rovereto: Nicolodi.

CABRERA i Massánes, P. (1998). La transformación urbana de Ciutat Vella. 1992-1998. (A. d. Barcelona, Ed.) Barcelona y Sociedad(9), 14-30.

FERNANDEZ M. (2012). Fernández González, Miquel. Matar al "Chino" Entre la revolución urbanística y el asedio urbano en el barrio del Raval de Barcelona. Barcelona: Tesis Doctoral. Dir. Delgado, M.; Martínez Sanmartí,

ITRIAGO, C. (2006). Sobre copias, transformaciones y omisiones. La recomposición de las ciudades devastadas. Barcelona. Tesis Doctoral. Dir. Peremiquel, $F$.

VERGARA, A., RIVAS Sanz, J., \& LERNER, J. (2004). Territorios inteligentes: nuevos horizontes de urbanismo. Madrid: Fund Metrópoli.

Francesc Peremiquel Lluch - Dr. Arquitecto Professor titular del Departament de Urbanisme i Ordenació del Territori - UPC peremiquel@coac.ne 